\title{
VIETNAMESE ENGINEERING STUDENTS' PERCEPTIONS OF THE USE OF GOOGLE TRANSLATION TOOL
}

\author{
NGA THI TUYET PHAN ${ }^{1}$, CHENG-HU CHEN ${ }^{2}$ \\ ${ }^{1}$ Industrial University of Ho Chi Minh City, Vietnam \\ ${ }^{2}$ National Ilan University, Taiwan \\ ngaphan@iuh.edu.vn
}

\begin{abstract}
The study looked at how Google Translate was used among a group of engineering students to learn TOEIC at a university in Southern Vietnam. This research took a form of a qualitative case study with semi-structured interviews and observations being the data collection tools. Findings suggested that this translation tool, in essence, was perceived to offer certain benefits to the students. For example, it was fast, convenient and helped students catch the gist or the general meaning of the source language quickly. Google Translate, however, failed to support reliable and understandable translation if the source texts contained technical terms, complex words, uncommon texts and meanings which perplexed the students. These limitations of this machine translation tool should be fully aware by engineering students and general language users who are not intermediate or advanced learners of English if it is to be used in translating tasks in the future. Suggestions on how to improve the limitations of Google Translate are mentioned in this study.
\end{abstract}

Keywords: Google Translation tool, Qualitative, translation

\section{INTRODUCTION}

According to Elshiekh [1], the use of machine translation in communicating, writing or translating documents has become popular in the recent years among language learners and users. The large volumes of documentations needed to be translated into another language seem to be expensive, slow, and laborious for human translation alone to meet such demand. There has been a number of machine translation tools designed so far such as Microsoft translator, Amazon translate, Bing Translator, and Yandex Translate. Among these tools, Google Translate is considered as the leading and most widespread worldwide available to the public [2] with a billion translations a day for millions of users [3]. Research into machine translation, however, remains scant [4]. A handful of research has looked at the quality and problems of translated texts by machine translation. In the Vietnamese context, there has been a gap in the literature investigating how machine translation in general and Google Translate Service in particular are used in practice despite their increasingly important role in social, business, and academic fields. Accordingly, this study was designed to extend our current understanding of how Google machine translator is being used in Vietnamese academic contexts, that is, how engineering students used the tool in translating English-to-Vietnamese texts and other tasks in an English language class. We also investigated the students' perceptions of the benefits and limitations of the service based on their personal experiences. The reason for choosing engineering students as participants for the present study was mainly because in the settings where English is not the mother tongue, engineering students resort to a translation tool while studying English more often than English majors. As a lecturer of English at a Vietnamese technical university who teach English for both kinds of students, the first researcher observed that Google Translation has been popular among engineering students in the recent years; however, as stated above, it has not been clear how the students use it and how they perceive the role of the tool in this special context. Therefore, findings of our study would be potential to provide students, teachers, and general users with a view of the benefits and limitations of this tool so as to make their own decision.

The following questions were addressed to obtain the objectives of the study:

1. How do engineering students use Google Translation Tool in their English study?

2. What are the perceived benefits and limitations of the tool? 


\section{LITERATURE REVIEW}

\subsection{Machine Translation and Google Translation Tool}

Baker and Saldanha [5] defined machine translation (MT) as "the use of computer programmes to translate texts from one natural language into another automatically" (p. 165). According to Allué [6], the application of new technologies to the field of linguistics gave birth to the so-called automatic or MT. MT is "a sub-field of Natural Language Processing" and an area of information technology [7]. The aim of MT is to produce the best translation without human assistance [8]. Texts of the input language are compared with samples of languages stored in the database [4]. MT adopts three models, namely the reordering order, word translation model, and phrase translation model. Korosec [9] stated that:

MT does not simply involve substituting words in one language for another, but applies complex linguistic knowledge to the text and/or selects the most probable words and sentence sequences from huge corpora of already existing translations (p.9).

Being an "important member of the Google family" [10], Google Translate (GT) is an automatic complimentary machine-translation service launched by Google in 2006. Like other machine translation tools, it depends on computer technology and software to translate words, sentences, paragraphs, and websites from one source language to another instantly [11]. A conventional phrase-based MT method, which was claimed to be inconvenient and time consuming since it was not an "end-to-end fashion" [12] and needed English as a bridging language, was replaced by a sentence-based method in 2016. The improved service which looks into broader contexts at a sentential level instead of a phrasal level can increase levels of translation accuracy up to around 55-85\% [4]. Besides, the updated version can translate the source language to the target language directly which speeds up the translation process and improve its robustness [12].

GT has recently become the most popular MT tool since it runs on a huge database and offers more accurate translated texts compared to other MT applications [13]. It is freely and easily accessible to users since it offers both a website interface and mobile applications which they can use in their Android and IOS operating cell phones to translate texts into their selected languages. Since its birth, the service supports 103 languages at various levels [14], including Vietnamese and translates over 100 billion words a day [15]. More than five hundred million people from different places around the world use it for their own translating purposes [16].

\subsection{Relevant studies on the perceived translation quality of Google Translate}

Despite the popular use of Google Translate in academic fields, the number of studies examining the quality of its translated texts is limited. Results of available research show that language users have held different views of Google Translate. The following sections will discuss the benefits and limitations of GT pointed out in the literature.

According to a number of researchers (e.g. [17], [18], [19], GT has brought a number of benefits to its users. For example, in a research conducted in 2018 by Kol et al. [19] among 25 tertiary English for Academic Purposes students, GT was claimed to help the students write more words and write faster by enabling them to look up for the meaning of unknown words quickly. Similarly, Chandra and Yuyun [18] investigated the practice of GT in writing in an Indonesian EFL class and their findings corroborated Kol et al.'s [19] study. The data gained from eight students showed that the EFL students perceived GT as a dictionary which supported them to find or translate vocabulary faster.

Medvedev [10] shared his participants' ideas regarding the advantages of GT. Omani students in an English Foundation Program in his study favored GT because it has a free access, is convenient and easy to use. The students downloaded the app in their smart phones and their learning became easier and effortless since the tool provided translated texts in a quick click.

In a similar vein, Maulidiya [20] listed a number of GT benefits in his study with twenty five EFL students in a translation course at a Malaysian university. The students stated that they were in favor of GT because it is complementary and easily accessible. GT helped them do exercises and assignments and get the meanings of words or phrases in the target language. Besides, the students could get translated texts quickly and the translation quality was believed to be far better than their own translation. 
In contrast, another group of researchers have pointed out some limitations of GT. Incorrect translation and post-editing requirement have been reported to be the most serious issues caused by GT. For example, in the study of Egamberdievna and Daminovna [21], oil and gas engineering students found the translated texts difficult, sometimes misleading, to understand. The reported grammatical, lexical, morphologicalsyntactic errors found in such translated texts caused some ambiguity and inaccuracies which hindered the students from understanding the translation products and made them doubt the translation quality and usability. Similarly, a number of researchers agreed that the translation provided by GT requires extensive editing due to its problem in identifying "sentence structures, styles, and writing identity" [22], and "word usage and omission" [23]. Groves and Mundt [13] explained that GT lacks the ability to "satisfy the norms of a discourse community" when dealing with the translation that go beyond the sentential level. It may be due to the differences between the source and the target languages [24].

Researchers have mentioned variations in the accuracy levels of texts translated by GT. For instance, Western languages such as English and Spanish are generally translated accurately, and the accuracy of African languages is often the poorest, followed by Asian languages [25]. Google Translate performs well especially when English is the target language and the source language is from the European countries [26]. Previous studies have pointed out GT's problems in translating Asian languages [27]. Accordingly, Groves and Mundt [13] called for more research investigating the quality of translated texts from Asian languages into English and vice versa. Moreover, in most of the studies reviewed above, participating students were English majors at intermediate or advanced levels. Therefore, they were aware of the errors and able to edit most possible mistakes made by GT. Our study, accordingly, aims to fill these gaps by examining the use of GT in the Vietnamese academic context and GT's translation quality perceived by engineering students whose English proficiency levels are not that good.

\section{METHOD}

\subsection{Research Context and Participants}

The study was carried out during the second semester of the 2019-2020 academic year. Participants in the study were 6 engineering sophomores, 2 males and 4 females, studying at a technical university in Southern Vietnam. They majored in Electrical Engineering, Mechanical Engineering, and Automatic Engineering. The students attended an English 2 course which was designed to help them target at least 351 TOEIC (Test of English for International Communication) scores in approximately 15 weeks. The textbook used for the course is TOEIC Preparation, Volume 1. The book includes authentic listening and reading texts, covering a range of topics and contexts including transportation, offices, health, banking, industry, jobs, travel, housing, entertainment, and restaurants. Idioms and expressions are frequently found in the book.

\subsection{Methodology and Research instruments}

In order to understand engineering students' perceptions of the use of GT, the research took the form of qualitative methodology as this paradigm is known to take participants' perspectives and experiences as central, acknowledging the complex interactions of socio-cultural factors and reporting multiple perspectives [28]. Rahman [29] stated that:

Qualitative methodology can refer to research about persons' lives, lived experiences, behaviors, emotions, and feelings as well as about organizational functioning, social movements, cultural phenomena, and interactions between nations.

Flick [30] also claimed that:

Qualitative research interested in analyzing subjective meaning or the social production of issues, events, or practices by collecting non-standardized data and analyzing texts and images rather than number and statistics.

In the present study, non-participant observations and semi-structured interviews were used to gather data to answer three research questions mentioned above. The researchers used non-participant observation as an additional data tool for the present study because this research instrument allowed us to understand the phenomenon in context while still being separated from what we tried to observe [31]. Observations helped contextualize findings from interviews and ensured that the data from interviews were reliable [32]. Semistructured interview is considered as one of the most commonly used qualitative data tools [33] as it allows for "an open response in the participants' own words rather than yes or no answer" [34]. Besides, the 
interaction between the first researcher and each participant gave more opportunities for the researcher to "investigate the world of individuals in depth" [31].

In our study, after the sixth week of the English 2 course, engineering students were invited to participate in a 60-minute individual interview in which they had opportunities to talk about how they used GT in their TOEIC classrooms and what they thought about GT's performance and the quality of texts translated by GT. After the eighth individual interview ended at week 9 of the course, the first researcher conducted four observation sessions in the students' TOEIC classrooms. Observation focused on what the students did and said in their TOEIC class in relation to their use of GT. Each classroom observation session lasted 50 minutes and the observation period lasted a month. The first researcher came to each observation session with a guideline in which she took notes of a) participants' frequency and duration of using GT; b) contents of translation texts; c) conversations with partners or the teacher regarding the translated texts. She sat in silent next to the participants to observe and take notes. Each interview was audio recorded. Notes were taken during individual interviews and observations. Follow-up interviews were arranged after each observation session to validate data. The first researcher got some participants explanation for certain behaviors in the classroom during the follow-up interviews.

\subsection{Data analysis, validity and reliability}

Thematic analysis [35] was used in the study. The researchers coded for each specific research question. In order to ensure the reliability and validity of the research, detailed descriptions of the study were provided and triangulation was employed. Regarding reliability, the research aims and research questions were made explicit. The research process was transparent owing to the provided details of data collection methods, procedures and analysis. In terms of validity, two data tools were used and data were sought from 6 participants. Two researchers often discussed findings to warrant that the study themes emerged from the data.

\subsection{Ethical issues}

No real names of the participants were revealed in the study. The data received from participants were confidential. Participants' privacy was ensured and protected at all time.

\section{FINDINGS AND DISCUSSION}

\subsection{How do engineering students use Google Translation Tool in their TOEIC study?}

All participants said that GT was one essential tool in their TOEIC classroom. Participating students downloaded GT app into their smart phones and used it from there. Six students reported to use GT as a part of their study to translate English words, complex sentences, and paragraphs in the textbook into Vietnamese depending on how challenging they perceived the source texts were. Other usage of GT included checking spelling and pronunciation.

When reading the textbook to complete exercises, all students resorted to using GT to get "general word meaning", "understand several difficult words", and "understand English sentences and paragraphs". The participants described in details how they used GT to translate texts as in the following examples.

I inserted the English words I didn't know in the GT box and their meanings would appear. I used GT to look for words I didn't understand, just words only. Other than that I didn't use it because there are too many new words in the TOEIC textbook and I didn't have enough time in the classroom. (S1)

I mostly input single words in the box. Sometimes I translated the whole paragraph if the content made me confused. (S3)

At the beginning of a unit, there are usually two or three paragraphs discussing the main grammar points or test taking tips. These paragraphs really confused me. I often translated them directly. However, when I did the exercises at the end of the unit, I translated it word by word. (S5)

There were two out of six students who took advantage of GT to do other tasks along with translating. One student said that GT helped him to check English word spelling. He said:

For some exercises, for example, gap filling, I need to decide which word is the correct one to put in the blank. Sometimes if I think one word has a spelling mistake, which would probably be the wrong answer but I'm not really sure, GT helps me to look for the correct spelling. (S6)

GT helped the other student improved her pronunciation as she described: 
Correct pronunciation is very important in TOEIC listening. You cannot recognize the words if you don't pronounce them accurately. I use GT to check my pronunciation. I type English words in the GT box and listen to how they are pronounced. (S4)

Five out of six students reported to use GT alone. They did not combine the tool with another machine translator. Since they only needed "the gist" of a sentence or paragraph, using GT became their "habit" whenever they tried to understand "difficult words" or "confirm [their] understanding". S6 was the only participant in the study who combined both GT and Google in translating texts. He reported to search the web for the meaning of some grammar structures or technical words to achieve better translated products. He said:

To translate simple English words or sentences, I think Google is good enough to get a general understanding of their meaning. But to deal with a complex paragraph, I needed to look for any uncommon grammar structures or terminologies in the paragraph. I then typed them on Google to acquire the exact meaning. I translate the rest by Google Translate.

He also mentioned that it took more time but was more effective than the sole use of GT.

Data from observation sessions showed that the students were favor of GT whenever they confronted any difficulties in understanding the language of the textbook. Their teacher allowed cell phones in her classroom for English learning purpose only. In a learning period of 50 minutes, the approximate amount of GT using time per participant was 15 minutes. The students either typed or scanned the texts they wanted to understand the meaning in Vietnamese into the GT box on their cell phones. It took S6 more time than the rest of the students because he combined both GT and Google in finding the meaning of the words in Vietnamese. S4 frequently listened to English pronunciation on GT with her earphones.

Findings in our study suggest that all participating students appeared to know different functions of GT and used it quite often in their TOEIC classroom. The finding that six students mainly used GT as a dictionary is similar to what other researchers found in other academic areas. For example, in the study of Maulidiyah [20], Medvedev [10], and Kol et al. [19], GT appeared to be a useful learning tool for the students as it helped them to look up for the meaning of unknown words or translate the vocabulary they need into the target language faster.

In our study, engineering students not only used GT to translate English texts into Vietnamese but GT seemed to be useful in checking spelling and pronunciation. This is different from the ways students in the available literature used GT. In most of the reviewed studies, participants didn't mention such uses. Reasons for the difference are mentioned in the following section.

\subsection{What are the perceived benefits and limitations of the tool?}

Benefits For a limited number of features, GT pleased all participants in our study who accessed to it via their mobile application. The students recommended GT for its speed and easy-to-use interface. According to the students, on a smart phone, GT needed approximate one second to translate a text, no matter whether it was a word, a sentence, a paragraph or a whole long document. Besides, the students "didn't need to read any materials to understand how to use GT". Six students used positively words and phrases to praise these good features of GT: "easy to use", "very easy and simple to use', "convenient", "easy to use and understand", "just in a click", "everybody's translator". The students appreciated GT for its time-saving feature.

In our study, GT is claimed to produce good results regarding translating simple texts with participants' satisfaction level ranging from $60-70 \%$ for accuracy. Words having common meaning and basic or nonspecialized sentences were reported to be the best for GT to perform well. Participating students showed their appreciation of GT's translation accuracy in this specific area.

The findings that GT provided users with readable and good translated products for the simple and nonspecialized texts are similar to what researchers found in their study. For example, in McGuire's [15] study, GT was said to translate texts with the common use of words and phrases in a consistent manner. He also noted that this machine translation tool was rated 5.43 on a satisfaction level ranging from 0 to 6 with native speakers' participants.

Limitations All participants complained about the accuracy levels of translated uncommon structures, complex grammatical items and terminologies. For example, one student said: 
GT is quite good at providing common meaning for the source texts. However, sometimes I didn't understand the translated grammatical structures in Vietnamese because the meaning was weird. (S2)

Another common limitation that all the participants mentioned was the fact that GT could not provide context appropriateness for translated texts. They showed their disappointment.

GT let me down. The translated language is not appropriate to the language used in statistics. It irritated me when reading the result because the words did not match the context. (S1)

GT tends to be wrong in context when working with long sentences or complex sections. (S6)

After using GT to translated statistical paragraphs or uncommon phrases, some students spent time editing the products.

GT's translated texts sometimes need edition. I went to Google check its translation again. It took me quite a lot of time. (S6)

Observation data shed more light on this finding. In their TOEIC classroom, participants often discussed with their classmates to clarify the meaning of translated texts after using the service. Sometimes, they requested their teacher's help. Participant explained in follow-up questions:

I sought classmates' help. I couldn't figure out the meaning of uncommon phrases from GT. (S4)

Sometimes I asked my friend for helping with the meaning of translated grammatical items. When he couldn't, the teacher helped us. Not easy for us. (S3)

Other important limitations were pointed out by two participants in our study. GT did not save the history of translated list, which appeared to be inconvenient for frequent users since it took long time to type those words again. Second, GT could not work without an Internet connection. Consequently, the participant said he delayed their translation process unwillingly.

I do not understand why Google did not save the translated history. This drove me mad sometimes because I couldn't remember all words that I had just translated. I needed to do it again. Waste my time, you know!

I think Google has a big gap in the development process. Users can only use GT when there is an Internet connection. I cannot translate documents without the Internet! Very inconvenient! (S1)

The above findings corroborate Egamberdievna and Daminovna's [21], Kirchoff et al.'s [22], and Sheppard's [23] assertion that GT's translated products needs improvement regarding syntactic and vocabulary features, especially in technical documents containing specialized terms, in order to "produce accurate translations of original content". Elshiekh [1] explained that it is hard for a machine to understand and meet the needs of human since "the meaning of English words is infinite for it to perform by selecting a certain sense for a certain context stored in its database".

In the study, the participants expressed that it required post-editing and correction to create a better quality translated product after using GT. This finding supports the work of Van Rensburg et al. [36] and Dew et al. [37] in which the participants stressed that this machine translator was "unreliable for direct using" and "human translators needed to amend these errors" to achieve the best results.

Findings in our study have some important implications. First, since engineering students are not professional translators or English majors, the limitations of GT need to be raised among them. Teachers and educators may want to encourage the students to use additional learning tools such as a dictionary to check the meaning of translated texts in case the quality and accuracy do not match the need. Group discussion and teacher help for clarifying such meaning are also important to the students' English learning. Second, GT's development team may want to improve the limitations mentioned in this study. Once such limitations as inaccuracy and unsaved translated history are fixed, GT is sure to become the most important language learning tool for all language users worldwide.

\section{COCLUSION}

Our study draws attention to the lack of research investigating the use of GT in academic contexts in general and in engineering education in particular. In the present study, six engineering students often accessed GT on their smart phones to translate simple or complex words, phrases, sentences, paragraphs and documents from English into Vietnamese. Findings showed that GT offered a number of benefits, including its fast speed and easy-to-use interface which pleased its users. GT, however, had some limitations that need 
improving to satisfy language users' demands. It has difficulties in translating complex and specialized words. Besides, the translated meaning and context of words often disappointed participants. Post-edition or modification to achieve a better translation quality was required. For non-English majors like six engineering students in our study, in order to take full advantages of GT, it is important to make them aware that GT provides satisfactory translation with source texts containing common words, phrases and simple sentences. For other cases, users should apply other translation tools, dictionaries or professional help to achieve optimal results.

Our study is not without limitations. The findings of our study cannot be generalized owing to the limited number of participants. Besides, the present research only reviewed studies which are published and written in English. Therefore, it is likely that the researchers have missed some important unpublished research written in Vietnamese. In addition, as artificial intelligence is improved constantly, it would be useful to conduct similar studies in different settings with larger samples of engineering students using GT to learn TOEIC in the future to validate and extend findings of our study.

\section{REFERENCES}

[1] A. A. Elshiekh, Google Translate Service: Transfer of Meaning, Distortion or Simply a New Creation? An Investigation into the Translation Process \& Problems at Google. Published by Zarqa University, 2012.

[2] S. Seljan, M. Brkić, and V. Kučiš, Evaluation of Free Online Machine Translations for CroatianEnglish and English Croatian Language Pairs. In Proceedings of the 3rd International Conference on the Future of Information Sciences: In Future2011-Information Sciences and e-Society, 331-345, 2011. Zagreb, Croatia.

[3] S. Shankland, Google Translate Now Serves 200 Million People Daily. CNET, 2013. Retrieved from http://news.cnet.com/8301-1023_3-57585143-93/googletranslate-now-serves-200-million-peopledaily/

[4] A.Tongpoon-Patanasorn and K. Griffith, Google Translate and Translation Quality: A Case of Translating Academic Abstracts from Thai to English, PASSA, 134-163, 2020

[5] M. Baker, and G. Saldanha, Routledge Encyclopedia of Translation Studies, 2nd Edition. London and New York: Routledge, 2008.

[6] B. Allué, The reliability and limitations of Google Translate: A bilingual, bidirectional and genrebased evaluation. Universidad de Zaragoza, 1, 2017. Retrieved from https://www.academia.edu/34762760/The_Reliability_and_Limitations_of_Google_Translate_A_Bilingu al_Bidirectional_and_Genre-Based_Evaluation

[7] S. Çakır, A study on the efficiency of "Google Translate" translation program. A Study on the Efficiency of The Google Translate Translation Program, 2013.

[8] A. Z. Algani, and Z. Omar, Arabic to English machine translation of verb phrase using rule-based approach. Journal of Computer Sience, 8 (3), 277-286, 2012.

[9] M. K. Korosec. Applicability and Challenges of Using Machine Translation in Translator Training. Language, 7-18, 2020. 
[10] G. Medvedev, Google Translate in Teaching English. The journal of teaching English for specific and academic purposes, 4 (1), 181-193. Retrieved from http://espeap.junis.ni.ac.rs/index.php/espeap/article/view/318/221

[11] C. Boitet, B. Hervé, S. Mark and B. Valérie, Evolution of MT with the Web. In Proceedings of the Conference Machine Translation 25 Years On, 1-13. Cranfield: Bedfordshire, 2009.

[12] Y. Wu, M. Schuster, Z. Chen and Q. V. Le, Google's Neural Machine Translation System: Bridging the Gap between Human and Machine Translation, CoRR, vol. abs/1609.08144, 1-23, 2016.

[13] Groves, M., and Mundt, K. Friend or foe? Google translate in language for academic purposes. English for Specific Purposes, 37, 112-121, 2015.

[14] "About". Google Translate. Google. Retrieved November 28, 2018.

[15] McGuire, N. "How accurate is Google Translate in 2018?". ARGO Translation, 2018. Retrieved November 29, 2018.

[16] Turovsky, B. "Ten years of Google Translate", Google Translate blog, 2016. Retrieved from http://googletranslate.blogspot.com.es/

[17] P. Jaganathan, H. Maryam, S. Ilangko, An Analysis of Google Translate Use in Decoding Contextual Semanticity among EFL Learners, Asian Journal of Research in Social Sciences and Humanities Vol. 4, No. 9, pp. 1-13, doi: :10.5958/2249-7315.2014.00962.9, 2014.

[18] S. Chandra, and I. Yuyun, The use of Google Translate in EFL essay writing. LLT Journal, 21 (2), 228-238. 10.24071/1tt.2018.210212, 2018.

[19] Kol, S., Schcolnik, M., and Spector-Cohen, E. Google Translate in Academic Writing Courses?. The EuroCALL Review, 26(2), 50-57, 2018. doi:https://doi.org/10.4995/eurocall.2018.10140

[20] F. Maulidiyah, To Use or Not To Use Google Translate. Jurnal Linguistik Terapan, 8(2), p. 1-6, 2018.

[21] T. S. Egamberdievna and T. D. Daminovna, Statistical Analysis in Performance of GT (GoogleTranslate) Among Learners and Professor-Teachers \& Comparative Analysis in Translation of GT and Human Mind. Journal of Critical Reviews, 7 (8), 2607 - 2620, 2020.

[22] K. Kirchoff, M. Turner, A. Axelrod, and F. Saavedra, Application of statistical machine translation to public health information: A feasibility study. Journal of the American Informatics Association, 18, 473478, 2011. Also available online at http://www.ncbi.nlm.nih.gov/pmc/articles/PMC3128406/.

[23] F. Sheppard, Medical writing in English: The problem with Google Translate. La Presse Médicale, 40(6), 565-566, 2011. Also available online at http://www.emconsulte.com/en/article/293595.

[24] M. Costa-jussá, M. Farrús, and J. Pons, Machine translation in medicine: A quality analysis of statistical machine translation in the medical domain. Advanced Research in Scientific Areas, 2012. Retrieved from www.arsa-conf.com on December 8, 2018. 
[25] Freitas, C. Liu, Y. Exploring the Differences between Human and Machine Translation. Western Washington University: 5, 2017.

[26] P. Koehn, Statistical machine translation. New York: Cambridge, 2010.

[27] M. Aiken, and S. Balan, An analysis of Google Translate accuracy. Translation Journal, 16(2), 2011. Retrieved from http://www.bokorlang.com/journal/ 56google.htm on December 05, 2016

[28] W.J. Hutchins, The development and use of machine translation systems and computer based translation tools. International journal of translation, 15(1), 5-26, 2003.

[29] M. S. Rahman, The Advantages and Disadvantages of Using Qualitative and Quantitative Approaches and Methods in Language "Testing and Assessment" Research. Published by Canadian Center of Science and Education, 2017.

[30] U. Flick, An introduction to qualitative research (5th ed.). London: Sage Publications Ltd., 2014.

[31] R. Barbour, Doing focus groups. London: Sage, 2007.

[32] J. W. Creswell, Educational research: planning, conducting, and evaluating quantitative and qualitative research (4th ed.). Boston: Pearson, 2012.

[33] C. Marshall, \& G. B. Rossman, Designing qualitative research (5th ed.). Thousand Oaks, CA: Sage, 2011.

[34] K. Dunn, Interviewing in: Qualitative Research Methods in Human Geography. Oxford University Press, Australia, 79-105, 2005.

[35] V. Braun, and V. Clarke, Using thematic analysis in psychology. Qualitative Research in Psychology, 3(2), 2006. 77-101. 10.1191/1478088706qp063oa

[36] A. Van Rensburg, C. Snyman, and S. Lotz, "Applying Google Translate in a higher education environment: Translation products assessed". South African Linguistics and Applied Language Studies, 30, 511-524, 2012.

[37] K. Dew, A. M. Turner, L. Desai, N. Martin, A. Laurenzi, and Kirchhoff. KPHAST: A Collaborative Machine Translation and Post-Editing Tool for Public Health. AMIA . Annual Symposium proceedings. AMIA Symposium, 2015, 492-501, 2015.

\section{NHẬN THỨC CỦA SINH VIÊN CHUYÊN NGÀNH KỸ THUẬT VỀ VIỆC SỬ DỤNG CÔNG CỤ GOOGLE TRANSLATE}

Tóm tắt: Bài báo trình bày nghiên cứu về cách thức sinh viên chuyên ngành kỹ thuật của một trường đại học ở Việt Nam sử dụng công cụ Google Translate để học tiếng Anh TOEIC. Nghiên cứu này sử dụng phương pháp định tính, công cụ nghiên cứu gồm phỏng vấn bán cấu trúc và quan sát. Kết quả nghiên cứu cho thấy về cơ bản, công cụ Google Translate mang lại cho người học một số lợi ích như: thuận tiện, nhanh chóng, giúp người học hiểu được ý chính của văn bản gốc nhanh chóng. Tuy nhiên, nếu văn bản gốc có các 
từ kỹ thuật, chuyên ngành, những cụm từ không thông dụng hoặc các cấu trúc câu phức tạp thì công cụ Google Translate sẽ không cung cấp bản dịch chính xác và gây khó hiểu cho người học. Để phát huy tối đa những mặt tích cực của công cụ dịch này, người học trong tương lai, đặc biệt là những sinh viên chuyên ngành kỹ thuật mà trình độ tiếng Anh không cao, cần nhận thức rõ những mặt hạn chế của Google Translate. Những gợi ý khắc phục phù hợp cũng được đề cập trong nghiên cứu này.

Từ khóa: định tính, công cụ dịch Google, dịch thuật

Ngày nhận bài: 25/08/2020

Ngày chấp nhận đăng: 23/12/2020 